\title{
Numerical simulation of square section venturi scrubber for biomass tar removal
}

\author{
Zhenhui Luan ${ }^{\text {a }}$, Xiao Liu, Meng Zheng and Libo Zhu \\ School of Mechanical Engineering, Anhui University of Science and Technology, Huainan 232001, China
}

\begin{abstract}
In the process of biomass gasification, it is inevitable to produce by-products, among which the most important is the tar. With the continuous development of biomass gasification technology, a variety of tar removal methods have been developed. According to the principle of the process of tar removal, the two methods are physical and thermochemical. The venturi scrubber is physical wet decoking equipment, and it is an important part to improve the efficiency of removing tar. In order to improve efficiency of tar removal of venturi scrubber, the authors put forward square section venturi scrubber for removing the tar from biomass gas, modeled the venturi scrubber through the three-dimensional modeling software, carried out the numerical simulation, and obtained the velocity contours, pressure contours in several cases. The research indicates that the square tube has big pressure change. And the results of a venturi scrubber have a certain guiding role in engineering application.
\end{abstract}

Keywords: venturi scrubber; square section; biomass gas; tar; efficiency.

\section{Introduction}

The biomass gas not only can effectively relieve the energy in the form of tight supply, but also reduce air pollution due to the burning of agricultural waste, and is so popular with the attention of scholars both at home and abroad. In the process of biomass gasification, it is inevitable to produce by-products and other impurities, among which the most important is the tar. Tar has a larger viscosity, and for a long time, it will jam the pipeline or kitchen. In order to purify biomass gas, people has used various means to reduce the harm of $\operatorname{tar}[1]$. With the continuous development of biomass gasification technology, a variety of tar removal methods have been developed. According to the principle of the process of tar removal, the two methods are physical and thermochemical. The venturi scrubber is physical wet decoking equipment, it has better economy, so it is an important part to improve the efficiency of removing tar. Efficiency of biomass gas purification is very important to venturi scrubber, which determines venturi scrubber whether can be used in biomass gasification technology[2]. In order to improve removal efficiency of tar of the venturi scrubber, this paper established a model of the squaretube, selected some parameters, simulated the flow field and obtained some pressure and speed features of the tube.

a Corresponding author : zhluan@ aust.edu.cn

(C) 2016. The authors - Published by Atlantis Press 


\section{Build a model}

The physical model: Venturi scrubber is mainly composed of three parts of converging section, throat and diverging section. In converging section, washing liquid is sprayed by the nozzle into the biomass gas, the nozzle is installated in center of converging section[3]. First of all, the paper determined the geometrical dimensions of inlet pipe and outlet pipe of the square tube. Effects of inlet pipe are for the connection on the level of gas purification equipment, and at the same time can make the gas into the tube with a buffer stage. The role of the outlet pipe section is for mist device connected to the next level, and at the same time can make the pressure sufficient recovery phase.

The cross-sectional area for the inlet section of the tube $\mathrm{A}_{1}$ is

$$
\mathrm{A}_{1}=\frac{\mathrm{Q}_{1}}{3600 \mathrm{v}_{1}}
$$

where $\mathrm{Q}_{1}$ is flow of biomass gas into the inlet pipe, $\mathrm{v}_{1}$ is the average flow velocity of biomass gas.

For general situation, the current speed from the higher equipment to enter the tube is $10-13 \mathrm{~m} / \mathrm{s}$, here to selectedv 1 as $12 \mathrm{~m} / \mathrm{s}$.

For circular cross section as the diameter, with rectangular cross section for the hydraulic diameter. So the rectangular section hydraulic diameter is

$$
\mathrm{D}_{1}=\frac{4 \mathrm{~A}_{1}}{2 \mathrm{a}+2 \mathrm{~b}}
$$

where $\mathrm{a}$ and $\mathrm{b}$ are two rectangular side length respectively.

For a square, a equals b, so $D_{1}=100 \mathrm{~mm}$. The cross-sectional area for the outlet section of the venturi scrubber $A_{2}$ is

$$
\mathrm{A}_{2}=\frac{\mathrm{Q}_{2}}{3600 \mathrm{v}_{2}}
$$

where $Q_{2}=Q_{1} \frac{273.15+t_{2}}{273.15+t_{1}}, Q_{2}$ is flow of biomass gas out the outlet pipe, $t_{1}$ is the temperature at which the biomass gas into the tube, $t_{2}$ is the temperature of the biomass gas leaving the tube, $v_{2}$ is the average flow velocity of biomass gas leaving the tube.

For general situation, the current speed of biomass gas leaving the tube is $12-13 \mathrm{~m} / \mathrm{s}$.In engineering practice, in order to avoid processing complexity, usually take $\mathrm{D}_{1}=\mathrm{D}_{2}$.

The decoking mechanism of venturi scrubber is that biomass tar particles collide with the washing liquid particles due to the intense turbulent motion in throat section. This enables them fully collide and intercept biomass tar. In order to obtain good effect on decoking, the flow velocity of biomass gas through the throat section must be determined carefully. Table 1 shows the flow velocity of gas through the throat section for different uses[4].

Table 1. The flow velocity of gas through the throat section for different uses

\begin{tabular}{ll}
\hline Operating purposes & Gas velocity of throat section \\
\hline Capturing the particles less than $1 \mathrm{um}$ & $90-120 \mathrm{~m} / \mathrm{s}$ \\
Capturing the particles greater than $1 \mathrm{um}$ & $70-90 \mathrm{~m} / \mathrm{s}$ \\
Cooling of the gas & $40-70 \mathrm{~m} / \mathrm{s}$ \\
\hline
\end{tabular}

To determine the biomass gas velocity of the throat section as $90-120 \mathrm{~m} / \mathrm{s}$, the hydraulic diameter of the throat section of the tube $\mathrm{D}_{0}$ is

$$
\mathrm{D}_{0}=0.0187 \sqrt{\frac{\mathrm{Q}_{0}}{\mathrm{v}_{0}}}
$$


Where $\mathrm{Q}_{0}$ is flow of biomass gas through the throat, $\mathrm{v}_{0}$ is the average flow velocity of biomass gas through the throat of the tube. And here to determine $\mathrm{D}_{0}=50 \mathrm{~mm}$.

About contract angle $\alpha_{1}$ and expanding angle $\alpha_{2}$, normally the scope of contract angle for $21^{\circ}$ to $30^{\circ}$, according to [5], here to determine the contract angle $\alpha_{1}=22^{\circ}$. Expanding Angle scope is commonly $4^{\circ}$ to $7^{\circ}$, and here to determine the expanding angle $\alpha_{2}=6^{\circ}$.

After determining the parameters, the paper built the physical model as shown in Fig.1, and set up $3 \mathrm{D}$ modeling of the tube as shown in Fig.2.

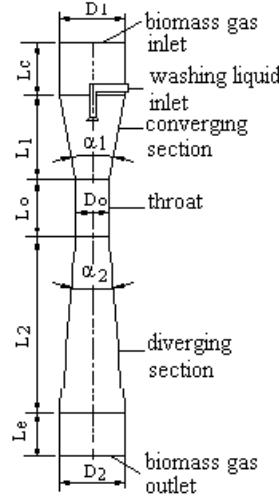

Figure 1. The physical model

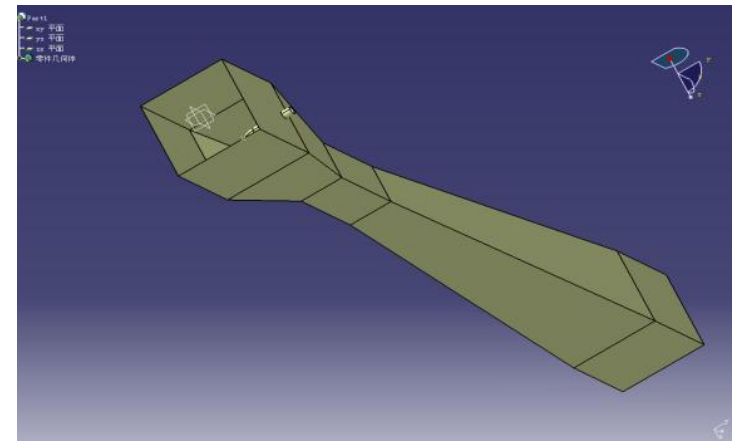

Figure 2. The 3D model of squaretube

The mathematical model: The transport equations of the standard $\mathrm{k}-\varepsilon$ model can be deduced as

$$
\begin{gathered}
\frac{\partial(\rho \mathrm{k})}{\partial \mathrm{t}}+\frac{\partial\left(\rho \mathrm{ku}_{\mathrm{i}}\right)}{\partial \mathrm{x}_{\mathrm{i}}}=\frac{\partial}{\partial \mathrm{x}_{\mathrm{j}}}\left[\left(\mu+\frac{\mathrm{u}_{\mathrm{i}}}{\sigma_{\mathrm{k}}}\right) \frac{\partial \mathrm{k}}{\partial \mathrm{x}_{\mathrm{j}}}\right]+\mathrm{G}_{\mathrm{k}}+\mathrm{G}_{\mathrm{b}}-\rho \varepsilon-\mathrm{Y}_{\mathrm{M}}+\mathrm{S}_{\mathrm{k}} \\
\frac{\partial(\rho \varepsilon)}{\partial \mathrm{t}}+\frac{\partial\left(\rho \varepsilon \mathrm{u}_{\mathrm{i}}\right)}{\partial \mathrm{x}_{\mathrm{i}}}=\frac{\partial}{\partial \mathrm{x}_{\mathrm{j}}}\left[\left(\mu+\frac{\mathrm{u}_{\mathrm{i}}}{\sigma_{\varepsilon}}\right) \frac{\partial \varepsilon}{\partial \mathrm{x}_{\mathrm{j}}}\right]+\mathrm{C}_{1 \varepsilon} \frac{\varepsilon}{\mathrm{k}}\left(\mathrm{G}_{\mathrm{k}}+\mathrm{C}_{3 \varepsilon} \mathrm{G}_{\mathrm{b}}\right)-\mathrm{C}_{2 \varepsilon} \rho \frac{\varepsilon^{2}}{\mathrm{k}}+\mathrm{S}_{\mathrm{k}}
\end{gathered}
$$

where $G_{k}=u_{i}\left(\frac{\partial u_{i}}{\partial x_{j}}+\frac{\partial u_{j}}{\partial x_{i}}\right) \frac{\partial u_{i}}{\partial u_{j}}, G_{b}=\beta g_{i} \frac{u_{i}}{p_{r f}} \frac{\partial T}{\partial x_{i}}, Y_{M}=2 \rho \varepsilon M_{i}^{2}, \quad p_{r f}=0.8$, and $\beta$ is thermal expansion coefficient, $\mathrm{M}_{\mathrm{i}}$ is turbulent Mach number, $\mathrm{C}_{1 \varepsilon}=1.44, \mathrm{C}_{2 \varepsilon}=1.92, \mathrm{C}_{3 \varepsilon}=0.99$, and $\sigma_{\mathrm{k}}=1.0, \sigma_{\varepsilon}=1.3$.

\section{Numerical simulation}

Set boundary conditions: In this paper, the boundary conditions of the tube were set by using ANSYS ICEM software. This paper set the inlet velocity as $12 \mathrm{~m} / \mathrm{s}$, set free flow as the outlet of the tube, set the biomass gas as continuous phase, and tar and washing liquid droplet as dispersed phase, set the inlet temperature of the biomass gas of the tube as $50^{\circ} \mathrm{C}$ and the outlet temperature of the gas as $30^{\circ} \mathrm{C}$, as the tube has the effect of the cooling fluid.

Numerical simulation: The paper carried out numerical simulation of the flow field by using FLUENT software. When the continuous phase achieved convergence, set an injection for washing liquid discrete phase, set the wall effect of particles, selected trap type as the inner wall of the tube, and selected escape type as the tube gas exports, and then iterated until convergence.

\section{Analysis and comparison with circular venturi tube}

The velocity characteristics: Fig. 3 is velocity contours of the tube, and Fig.4 is that of circular section one.

In Fig.3 and Fig.4, the velocity of the fluid has a gradient variation because of the converging 
section. As the pipe diameter reduces the velocity of the fluid increases rapidly, and it reaches maximum velocity when it is in throat. After throat the velocity reduces as the pipe diameter increases. It can be seen from the two diagrams that the velocity change uniformity in the square section is poorer than that in circular section one, but the maximum velocity in throat of the square section is greater than that of circular section one. There is a tail backflow at the end of the square tube, and this has a strengthening effect for tar removal.

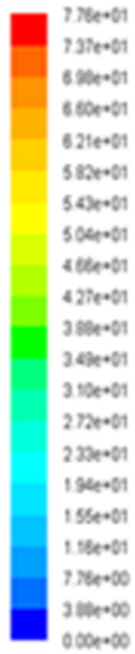

$\mathrm{m} / \mathrm{s}$

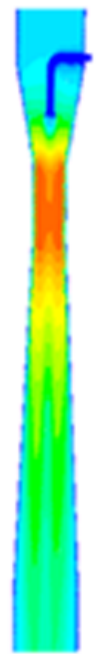

Figure 3. Velocity contours of square tube

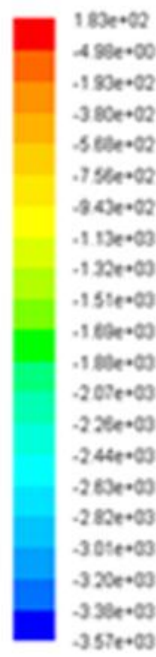

$\mathrm{m} / \mathrm{s}$

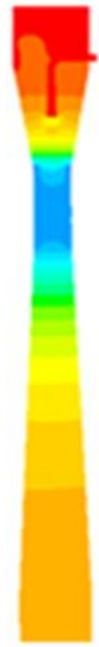

Figure 4. Velocity contours of circular tube

The dynamic pressure characteristics: Fig.5is the dynamic pressure contours of the square tube, and Fig. 6 is that of circular section one.

From Fig.5 and Fig.6, it can be seen that the numerical change of the pressure in squaretube is more intense, therefore the square tube has a strengthening effect for decoking

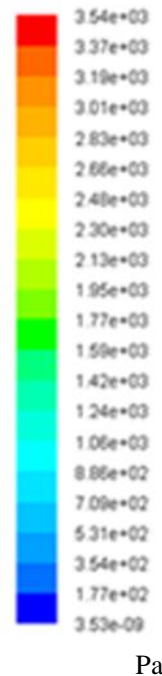

$\mathrm{Pa}$

Figure 5. Dynamic pressure contours of square tube
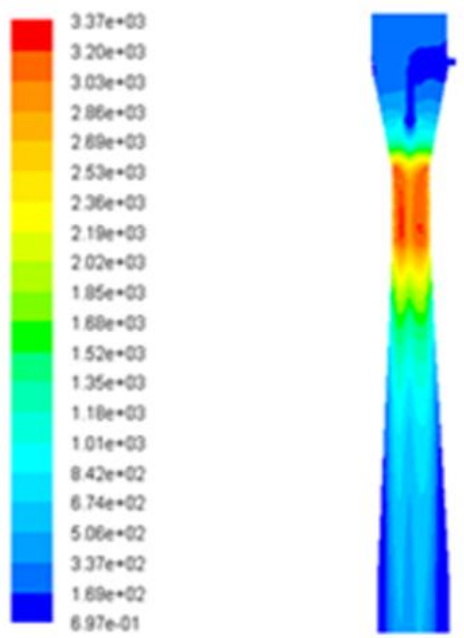

$\mathrm{Pa}$

Figure 6. Dynamic pressure contours of circular one

\section{Conclusion}

The pressure loss includes wall friction loss droplet acceleration pressure loss and gas-liquid mixing 
pressure loss. The flow uniformity of the squaretube is poorer than that of circular tube and the wall friction of the square tube is also bigger, and there is a tail backflow at the end of the squaretube, so the pressure loss of the squaretube is bigger than that of circular one, and the biomass tar removal efficiency of the square tube is higher than that of circular tube.

\section{Reference}

1. Chen Lianguo, Chen Zhili, et al. Gas and Heat, 2013,33(11)(In Chonese).

2. WangYan, Chen Wenyi, et al. Chemical Industry and Engineering Progress.2012,31(8)(In Chonese).

3. Dang yuchun, Liu hongbin, Ding qingguo.Journal of Chinese Agricultural Mechanization, 2014,35(2)(In Chonese).

4. Wang Chun, Zhang Dianyin. Dust Removal Equipment Manual. Chemical Industry Press, 2009(In Chonese).

5. L.b. Zhu. Anhui University of Science \& Technology, 2016.5(In Chonese). 